\title{
AKSESIBILTAS DAN PARTISIPASI POLITIK PENYANDANG DISABILITAS DI KABUPATEN JEMBER
}

\author{
Asrorul Mais ${ }^{1}$, Lailil Aflahkul Yaum ${ }^{2}$ \\ IKIP PGRI Jember ${ }^{1,2}$ \\ asrorulmais.plb@gmail.com ${ }^{1}$
}

\begin{abstract}
ABSTRAK
Penelitian ini bertujuan untuk mendeskripsikan 1) regulasi/peraturan terkait penyelenggaraan Pemilu bagi disabilitas dan implementasinya, 2) kendala yang dihadapi untuk mewujudkan pemilu akses bagi disabilitas, 3) upaya mewujudkan pemilu akses bagi disabilitas dan 4) peran penyandang disabilitas untuk berpartisipasi dalam politik. Metode dalam penelitianini menggunakan deskriptif kualitatif. Hasil penelitian menunjukkan bahwa Undang-undang pemilu dan penyandang disabilitas telah mengakomodir hak penyandang disabilitas dalam berpolitik. Sedangkan kendala yang dihadapi berupa kendala structural dan kultural dari pemerintah, masyarakat dan penyandang disabilitas. adapun upaya yang dilakukan KPU Jember untuk mewujudkan pemilu akses adalah membangun komunikasi dengan organisasi disabilitas dan membentuk relawan demokrasi dari segmen disabilitas. Penyandang disabilitas baik secara pribadi maupun secara organisasi ikut aktif melaksanakan diskursus dan memberikan saran kepada pemerintah dan KPU untuk terwujudnya perbaikan pemilu akses. Dari hasil penelitian dapat disimpulkan bahwa sesuai dengan UU pemilu tentang disabilitas KPU terus berupaya untuk mengikutsertakan penyandang disabilitas dalam pemilihan untuk memdahkan dan melauani hak pilih disabilitas.
\end{abstract}

Kata Kunci: Aksesibilitas, Partisipasi, Politik, Disabilitas

\section{ABSTRACT}

This study aims to describe 1) regulations related to election implementation for disability, 2) constraints in realizing election access for peoples with disabilities, 3) efforts to realize election access for peoples with disabilities and 4) the role of peoples with disabilities to participate in politics. The method in this research uses descriptive qualitative. The results of the study indicate that the election law and peoples with disabilities have accommodated the rights of persons with disabilities in politics. While the obstacles are structural and cultural constraints from the government, the society and people with disabilities. As for the efforts made by the Jember Ellection Committee to realize elections access is to build communication with disability organizations and form democratic volunteers from the disability segment. Peoples with disabilities both personally and in organizations actively carry 
out the discourse and provide advice to the government and Jember Ellection Committee for the realization to improve electoral access. From the results of the study it can be concluded that in accordance with the Election Law on disability the $K P U$ continues to make efforts to include persons with disabilities in elections to reduce and disability to vote.

Keywords: Accessibility, Participation, Politics, Disability

\section{PENDAHULUAN}

Menurut data UNESCAP jumlah penyandang disabilitas di Indonesia berada sekitar $1 \%$ dari jumlah penduduk, mengacu dari persentase data tersebut, pada tahun 2014 jumlah penyandang disabilitas sebanyak 2.523.707 jiwa. sedangkan data Kementerian Kesehatan menunjukkan jumlah penyandang disabilitas adalah 3.063.559 jiwa, sementara menurut data Kementerian Kesejahteraan Sosial jumlahnya mencapai 3.838.985 jiwa. Jika jumlah penyandang disabilitas secara kasar adalah 3.000.000 jiwa, maka sekitar 75\%-nya, yaitu 2.250.000 juta, tercatat sebagai pemilih. Jika satu kursi di DPR-RI pada Pemilu 2014 setara dengan 223.000 suara, maka seluruh suara penyandang disabilitas setara dengan 10 kursi DPR. Tentunya Jumlah yang cukup berarti dan layak diperhitungkan oleh partai politik dan calon legislatif.

Namun sangat disayangkan, hal di atas adalah hanya hitung-hitungan di atas kertas saja, secara realita tidak demikian adanya. Berbagai kendala sering dijumpai oleh para panyandang disabilitas untuk berpartisipasi dalam politik praktis, kendala yang dihadapi bisa berupa kebijakan, teknis, dan inklusifitas dalam sosial masyarakat. Robert (2001) menyatakan bahwa dalam sistem demokrasi, ikut serta dalam pemilihan umum merupakan hak politik bagi setiap warga negara.
Hak ini menyangkut hak untuk menyelidiki/ menjajaki alternatif yang ada dan hak untuk berpartisipasi dalam memutuskan siapa yang akan dipilih. Hak Politik inilah yang kurang mendapat porsi yang wajar untuk diperhatikan oleh pemerintah dalam pemenuhannya sehingga berdampak adanya sikap apatis dan pasif bagi penyandang disabilitas untuk berpartisipasi di bidang politik baik sebagai pemilih, penyelenggara, dan orang yang akan dipilih. Hal ini sudah diatur dalam pasal 5 Undang-Undang Nomor 7 Tahun 2017 tentang Pemilihan Umum yang menyatakan bahwa penyandang disabilitas yang memenuhi syarat mempunyai kesempatan yang sama sebagai pemilih, sebagai calon anggota DPR, sebagai calon anggota DPD, sebagai calon Presiden/Wakil Presiden, sebagai calon anggota DPRD, dan sebagai Penyelenggara Pemilu.

Mattila (2017) dalam penelitiannya di negara-negara Eropa mengemukakan bahwa terdapat penurunan jumlah partisipasi penyandang disabilitas dalam pemungutan suara, respon terhadap politik praktis dan keikutsertaan dalam demonstrasi menyikapi kondisi politik yang ada, hal terjadi karena adanya perilaku social yang masih bersikap diskriminatif terhadap disabilitas.

Sejalan dengan hal di atas Daulay (2013) menyatakan bahwa 
dalam konteks pemilu, pemberdayaan dan peningkatan peran para penyandang disabilitas dalam pembangunan nasional perlu mendapat perhatian dan pendayagunaan yang khusus. Namun selama ini, mereka belum mendapatkan hak untuk memperoleh kesempatan dan perlakuan agar bisa bertindak dan beraktivitas sesuai dengan kondisi mereka. Masih terjadi pengabaian hak politik penyandang disabilitas dalam Pemilu, antara lain Hak untuk didaftar guna memberikan suara; akses ke TPS, pemberian suara yang rahasia, dipilih menjadi anggota Legislatif, informasi termasuk informasi tentang pemilu, ikut menjadi pelaksana dalam pemilu (Muladi, 2009).

Hal ini juga didukung oleh Prince (2012) dalam penelitiannya di Kananda menyatakan bahwa ketika sistem dalam sebuah politik melibatkan dan memberi kesempatan yang setara dan sama kepada penyandang disabilitas untuk berpartisipasi dalam hal demokrasi, maka hal ini dapat meningkatkan motivasi dan perasaan optimis pada penyandang disabilitas untuk ikut serta dalam politik dan mendukung pelaksanaan demokrasi tersebut.

Dalam Konteks Kabupaten Jember, hal yang sama juga terjadi. Di Kabupaten Jember Berdasarkan data hasil Survei Sosial Ekonomi Nasional Tahun 2011 memiliki penduduk sebanyak 2.345.851 jiwa, Jika prevalensi penduduk penyandang diabilitas sebesar $1 \%$, maka setidaknya terdapat 23.000.000 penduduk penyandang disabilitas di Kabupaten Jember.

Namun dari data KPUD Jember, daftar pemilih tetap hanya sejumlah
1.616 jiwa atau setara dengan $0,09 \%$ dari seluruh DPT sejumlah 1.892.435 jiwa, berikut sebaran DPT di seluruh kecamatan di Kabupaten Jember tahun 2015. Dari data tersebut di atas tampak bahwa adanya permasalahan pendataan khususnya DPT penyandang disabilitas yang seluruhnya belum terdata dengan baik

Tabel 1. Perbandingan Daftar Pemilih Tetap Difabel dan Daftar Kehadiran Pemilih Disabilitas Tahun 2015

No Kecamatan $\begin{gathered}\text { DPT } \\ \text { Difabel }\end{gathered}$ Partisipasi $\%$

\begin{tabular}{clccc}
\hline 1 & AJUNG & 50 & 0 & 0.00 \\
\hline 2 & AMBULU & 48 & 1 & 2.08 \\
\hline 3 & ARJASA & 48 & 3 & 6.25 \\
\hline 4 & BALUNG & 35 & 2 & 5.71 \\
\hline 5 & BANGSALSARI & 67 & 1 & 1.49 \\
\hline 6 & GUMUKMAS & 59 & 0 & 0.00 \\
\hline 7 & JELBUK & 12 & 0 & 0.00 \\
\hline 8 & JENGGAWAH & 59 & 3 & 5.08 \\
\hline 9 & JOMBANG & 55 & 0 & 0.00 \\
\hline 10 & KALISAT & 76 & 44 & 57.89 \\
\hline 11 & KALIWATES & 55 & 2 & 3.64 \\
\hline 12 & KENCONG & 34 & 0 & 0.00 \\
\hline 13 & LEDOKOMBO & 0 & 0 & 0.00 \\
\hline 14 & MAYANG & 51 & 2 & 3.92 \\
\hline 15 & MUMBULSARI & 5 & 0 & 0.00 \\
\hline 16 & PAKUSARI & 16 & 0 & 0.00 \\
\hline 17 & PANTI & 53 & 0 & 0.00 \\
\hline 18 & PATRANG & 11 & 11 & 100.00 \\
\hline 19 & PUGER & 262 & 0 & 0.00 \\
\hline 20 & RAMBIPUJI & 36 & 32 & 88.89 \\
\hline 21 & SEMBORO & 25 & 0 & 0.00 \\
\hline 22 & SILO & 64 & 13 & 20.31 \\
\hline 23 & SUKORAMBI & 11 & 1 & 9.09 \\
\hline 24 & SUKOWONO & 24 & 1 & 4.17 \\
\hline 25 & SUMBERBARU & 129 & 0 & 0.00 \\
\hline & & & & \\
\hline
\end{tabular}




\begin{tabular}{|c|c|c|c|c|}
\hline No & Kecamatan & $\begin{array}{c}\text { DPT } \\
\text { Difabel }\end{array}$ & Partisipasi & $\begin{array}{l}\text { \%ang diselidiki (Cevilla,1993). } \\
\text { Maxfield menjelaskan bahwa peneitian }\end{array}$ \\
\hline 26 & SUMBER & 8 & 4 & $50.00^{\text {deskriptif termasuk dalam studi kasus }}$ \\
\hline 27 & SUMBERSARI & 25 & 0 & 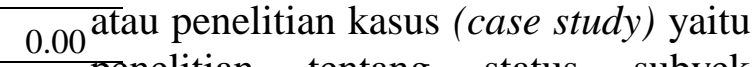 \\
\hline 28 & TANGGUL & 182 & 2 & $1.10^{\text {pene }}$ \\
\hline 29 & TEMPUREJO & 0 & 0 & $\begin{array}{l}\text { penelitian yang berkenaan den } \\
0.00 \text { suatu fase spesifik atau khas }\end{array}$ \\
\hline 30 & UMBULSARI & 56 & 0 & 0.00 keseluruhan personalitas. Adap \\
\hline 31 & WUL & 60 & 9 & 15.00tujuan dari studi kasus adalah ur \\
\hline & TOTAL & 516 & 131 & 8.11 memberikan \\
\hline
\end{tabular}

Dari data di atas, tingkat kehadiran pemilih disabilitas dalam pemilihan Bupati dana Wakil Bupati Tahun 2015 hanya sebesar 131 jiwa atau setara dengan $8,11 \%$, tentunya angka yang memperihatinkan ini memiliki alasan dan menarik untuk dikaji dan dianalisis lebih lanjut baik mulai dari segi Regulasi, Kendala, Upaya solusi dan peran disabilitas untuk berpartisipasi aktif dalam politik.

Berdasarkan uraian di atas, fokus penelitian ini adalah sebagai berikut : 1) Regulasi/Peraturan terkait penyelenggaraan Pemilu bagi Disabilitas dan implementasinya, 2) Kendala yang dihadapi untuk mewujudkan pemilu akses bagi disabilitas, 3) Upaya mewujudkan pemilu akses bagi disabilitas dan 4) Peran penyandang disabilitas untuk berpartisipasi dalam politik.

\section{METODE PENELITIAN}

Jenis penelitian deskriptif kualitatif digunakan dalam penelitian ini. penelitian deskriptif kualitatif merupakan suatu metode dalam meneliti sekelompok manusia atau suatu objek dengan tujuan membuat deskriptif, gambaran atau lukisan secara sistematis, faktual dan akurat mengenai fakta-fakta atau fenomena mendetail tentang latar belakang, sifatsifat serta karakter-karakter yang khas dari suatu kasus, ataupun status dari individu, yang kemudian dari sifat yang spesifik atau khusus tersebut akan dijadikan suatu hal yang umum (Nazir, 2013).

Tujuan penelitian deskriptif kualitatif adalah untuk mendeskripsikan apa-apa yang saat ini berlaku. Penelitian deskriptif kualitatif merupakan upaya mendeskripsikan, mencatat, analisis dan menginterpretasikan kondisi yang sekarang ini terjadi atau ada. Dengan kata lain penelitian deskriptif kualitatif ini bertujuan untuk memperoleh informasi mengenai keadaan yang ada (Mardalis, 1999)

Waktu dilaksanakan penelitian ini yaitu pada bulan Januari 2018 sapai dengan April 2019. Lokasi penelitian dilaksanakan di 31 Kecamatan di Kabupaten Jember dan bekerjasama dengan Oraganisasi Disabilitas di Jember dan Relawan Demokrasi Segmen Disabilitas Kabupaten Jember.

Dalam penelitian ini terdapat dua data yaitu data utama dan data pendukung. Adapun sumber data utama dalam penelitian ini adalah katakata dan tindakan atau peristiwa, sedangkan teknik yang digunakan yaitu dengan wawancara secara mendalam dan observasi. Teknik wawancara 
secara mendalam merupakan suatu proses interaksi dan komunikasi verbal dengan tujuan untuk mendapatkan informasi penting yang dibutuhkan dengan mengajukan sejumlah pertanyaan secara lisan untuk dijawab dengan lisan juga. Ciri utama teknik ini adalah adanya kontak langsung secara tatap muka antara pencari informasi dan sumber informasi (Zuriah, 2007). Adapun narasumber dalam deep interview adalah sebagai berikut

Tabel 2. Daftar Narasumber Wawancara

\begin{tabular}{|c|c|c|c|}
\hline No & Nama & Lembaga & Jabatan \\
\hline 1 & $\begin{array}{l}\text { Gogot } \\
\text { Cahyo } \\
\text { Baskoro, S. } \\
\text { Sos }\end{array}$ & $\begin{array}{l}\text { KPU Prov. } \\
\text { Jatim }\end{array}$ & $\begin{array}{l}\text { Divisi } \\
\text { SDM \& } \\
\text { Parmas }\end{array}$ \\
\hline 2 & $\begin{array}{l}\text { Ahmad } \\
\text { Hanafi, SE }\end{array}$ & $\begin{array}{l}\text { KPUD } \\
\text { Jember }\end{array}$ & $\begin{array}{l}\text { Divisi } \\
\text { SDM \& } \\
\text { Parmas }\end{array}$ \\
\hline 3 & $\begin{array}{l}\text { Moh. } \\
\text { Zaenuri } \\
\text { Rofi'I, SE, } \\
\text { S.Pd } \\
\text { (Tunadaksa) }\end{array}$ & $\begin{array}{l}\text { Perpenca } \\
\text { Jember }\end{array}$ & Ketua \\
\hline 4 & $\begin{array}{l}\text { Kusbandono, } \\
\text { S.Sos, M.Si } \\
\text { (Cerecral } \\
\text { Palcy) }\end{array}$ & $\begin{array}{l}\text { Relawan } \\
\text { Demokrasi } \\
\text { Segmen } \\
\text { Disabilitas } \\
\text { Kabupaten } \\
\text { Jember }\end{array}$ & Ketua \\
\hline 5 & $\begin{array}{l}\text { Nur Hayati } \\
\text { (Tuli) }\end{array}$ & $\begin{array}{l}\text { Gerkatin } \\
\text { Jember }\end{array}$ & Ketua \\
\hline 6 & $\begin{array}{l}\text { Rahman } \\
\text { Hadi, S.Pd } \\
\text { (Tunanetra) }\end{array}$ & $\begin{array}{l}\text { Pertuni } \\
\text { Jember }\end{array}$ & $\begin{array}{l}\text { Ketua } \\
\text { Dewan } \\
\text { Penasihat }\end{array}$ \\
\hline 7 & $\begin{array}{l}\text { Eko Puji } \\
\text { Purwanto, } \\
\text { SE } \\
\text { (Polio) } \\
\end{array}$ & $\begin{array}{l}\text { Disabilitas } \\
\text { Daksa }\end{array}$ & $\begin{array}{l}\text { Mantan } \\
\text { Caleg } \\
\text { Disabilitas }\end{array}$ \\
\hline
\end{tabular}

Sedangkan observasi yang digunakan dalam penelitian ini adalah observasi yang bersifat terus terang, yaitu peneliti dalam melakukan pengumpulan data menyatakan terus terang atau sejujur-jujurnya kepada sumber data bahwa peneliti sedang melakuan penelitian (Sugiyono, 2012). Dalam penelitian ini, observasi dilaksanakan di KPUD Jember, beberapa organisasi disabilitas di Kabupaten Jember dan pengamatan non-partisipan kepada masyarakat penyandang disabilitas itu sendiri. Data pendukung diperoleh dari beberapa dokumen yang ada pada lembaga terkait di atas dan observasi langsung tidak terstruktur.

Teknik triangulasi digunakan dalam penelitian ini agar data memiliki keabsahan, teknik yang digunakan adalah. Menurut Moleong (2010) Triangulasi adalah teknik pemeriksaan keabsahan atau validitas data yang memanfaatkan sesuatu yang lain di luar data itu untuk keperluan pengecekan atau sebagai pembanding terhadap data itu. Adapun cara melakukan trianggulasi dengan: (a) Membandingkan data hasil observasi dengan data hasil interview, (b) Membandingkan apa yang dikatakan orang di depan publik dengan apa yang dikatakan secara pribadi atau individu, (c) Membandingkan hasil interview dengan beberapa dokumen yang relevan.

\section{HASIL DAN PEMBAHASAN}

Regulasi/Peraturan Terkait Penyelenggaraan Pemilu Bagi Disabilitas dan Implementasinya

Pasal 5 Undang-Undang Nomor 7 Tahun 2017 tentang Pemilihan Umum menyebutkan bahwa "penyandang disabilitas yang memenuhi syarat mempunyai kesempatan yang sama sebagai pemilih, sebagai calon anggota DPR, sebagai calon anggota DPD, sebagai calon Presiden/Wakil Presiden, 
sebagai calon anggota DPRD, dan sebagai Penyelenggara Pemilu. Dengan adanya regulasi ini, pemerintah sebenarnya telah memberikan hak yang sama dan setara bagi penyandang disabilitas untuk berpartisipasi dalam politik. Hal senada juga termaktub dalam Pada pasal 5 Undang-Undang Nomor 8 Tahun 2016 tentang Penyandang Disabilitas bahwa Penyandang Disabilitas memiliki hak: a.hidup; b.bebas dari stigma; c.privasi; d.keadilan dan perlindungan hukum;e.pendidikan; f.pekerjaan, kewirausahaan, dan koperasi; g.kesehatan; h.politik; i.keagamaan; j.keolahragaan; k.kebudayaan dan pariwisata; l.kesejahteraan sosial; m.Aksesibilitas; n.Pelayanan Publik; o.Pelindungan dari bencana; p.habilitasi dan rehabilitasi; q.Konsesi; r. pendataan; s.hidup secara mandiri dan dilibatkan dalam masyarakat; t.berekspresi, berkomunikasi, dan memperoleh informasi; u.berpindah tempat dan kewarganegaraan;dan v.bebas dari tindakan Diskriminasi, penelantaran, penyiksaan,dan eksploitasi.

Sebagai konsekuensi dari negara demokrasi, maka implementasi dari demokrasi tentunya tidak bias lepas dari politik dan partisipasi semua warga negaranya dari politik khususnya dalam politik praktis tidak terkecuali bagi warga penyandang disabilitas. Oleh karena itu pemerintah mengatur dan memberikan hak yang sama dan setara bagi semua warga Negara untuk ikut serta dalam politik. Hal ini tentunya juga telah diterjemahkan dengan baik oleh Komisi Pemilihan Umum (KPU) pusat sampai daerah.
Wujud dari penerjemahan hak yang sama bagi penyandang disabilitas untuk berpolitik diimplementasikan oleh Komisi Pemilihan Umum berupa: a) KPU memberikan ruang yang sama kepada seluruh warga negara dalam berpartisipasi dalam pemilu, b) KPU berkomitmen untuk memberikan ruang yang sama dalam pemenuhan hak-hak bagi penyandang disabilitas dalam Pemilu yang meliputi hak politik, hak aksesibilitas, pelayanan publik, pendataan, berekspresi, berkomunikasi, dan memperoleh informasi serta bebas dari tindakan diskriminasi dan c) dalam penyelenggaraan setiap tahapan Pemilu, KPU memperhatikan aksesibilitas disabilitas untuk memastikan hak-hak politiknya terpenuhi dengan baik

Adapun tahapan-tahapan yang telah dilakukan oleh Komisi Pemilihan Umum dalam menjamin Pemilu akses dan menjangkau penyandang disabilitas antara lain: a) tahapan pemutahiran data pemilih, dalam tahapan ini, yang dilakukan adalah KPU melakukan klasifikasi data pemilih disabilitas untuk memudahkan penyelenggara Pemilu dalam melayani hak pilih disabilitas, dalam Daftar Pemilih Tetap (DPT) mencatat para pemilih berbasis TPS berdasarkan klasifikasi jenis kelamin dan kategori kelompok disabilitas yang terbagi dalam 5 kelompok, yaitu; 1.disabilitas daksa, 2. disabilitas netra, 3. disabilitas rungu/wicara, 4. disabilitas grahita dan 5.

Disabilitas lainnya, dengan itu, maka setiap TPS diharapkan akses terhadap disabilitas. b) tahapan sosialisasi, dalam tahap ini, sejak Pemilu 2014, KPU membentuk 
Relawan Demokrasi yang dibagi dalam 5 segmen yaitu; 1. Segmen Pemilih Pemula, 2. Segmen Pemilih Perempuan, 3. Segmen Pemilih Agama, 4. Segmen Pemilih Disabilitas dan 5. Segmen Pemilih Marginal. Masing-masing Relawan Demokrasi bertugas melakukan sosialisasi Pemilu di masing-masing segmen pemilihnya. Pada Pemilu 2019, KPU kembali membentuk Relawan Demokrasi dengan memperluas segmennya menjadi 10 (sepuluh) segmen pemilih yaitu; 1. Segmen Pemilih Pemula, 2. Segmen Pemilih Perempuan, 3. Segmen Pemilih Agama, 4. Segmen Pemilih Disabilitas dan 5. Segmen Pemilih Marginal, 6. Segmen Pemilih Keluarga, 7. Segmen Pemilih Netizen, 8. Segmen Pemilih Muda, 9. Segmen Pemilih Berkebutuhan Khusus dan 10. Segmen Pemilih Komunitas. c) tahapan kampanye, KPU memberikan kesempatan bagi penyandang disabilitas dalam penyelenggaraan debat pasangan calon dengan mengundang organisasi penyandang disabilitas dalam pelaksanaan debat. d) Tahapan Pemungutan dan Penghitungan Suara, dalam tahap ini, KPU menjamin TPS dalam memperhatikan kemudahan bagi pemilih disabilitas dengan cara: memastikan TPS tidak didirikan di lahan yang berbatu batu, berbukit, dikelilingi selokan atau parit,ataupun yang ada anak tangganya, tinggi meja bilik antara $75 \mathrm{~cm}$ sampai dengan 100 $\mathrm{cm}$ dari lantai dan setidaknya berjarak 1 meter antara meja dan dinding/pembatas TPS, tinggi meja kotak suara setidaknya $35 \mathrm{~cm}$ dari lantai, memastikan tidak ada bendabenda yang tergantung di langit-langit yang dapat membuat penyandang tuna netra terbentur, peralatan TPS diatur sedemikian rupa sehingga ada jarak yang cukup bagi pengguna kursi roda untuk bergerak secara leluasa di TPS dan menyediakan alat bantu tuna netra (Template).

\section{Kendala Yang Dihadapi Untuk Mewujudkan Pemilu Akses Bagi Disabilitas}

Meskipun secara yuridis hak penyandang disabilitas untuk turut serta berpartisipasi dalam politik sudah memiliki landasan hukum yang kuat, namun masih terdapat kendala dalam pengimplementasianya, kendala tersebut bisa berupa kendala struktural dan kendala kultural. Kendala struktural terjadi karena tingkat pemahaman yang belum sama diantara para penyelenggara pemilu yang tentunya tidak bersifat disengaja dan sering dilakukan oleh oknum, selain itu juga bisa disebabkan oleh beberapa kebijakan yang masih bersifat diskriminatif. Sedangkan kendala kultural disebabkan oleh kultur, budaya persepsi dan paradigma baik oleh masyarakat maupun penyandang disabilitas sendiri dalam menyikapai kondisi kedisabilitasan dikaitkan dengan perannya dalam politik dan pembangunan bangsa.

Beberapa contoh kasus yang sering muncul sebagai wujud dari kendala struktural yaitu: 1) masih sulitnya penyandang disabilitas untuk bisa mendaftar sebagai bagian dari penyelenggara pemilu mulai dari tingkat kabupaten sampai tingkat desa dikarenakan persyaratan pendidikan yang terlalu tinggi, sedangkan pada umumnya tingka pendidikan penyandang disabilitas cenderung rendah. 2) partai politik belum 
mengakomodir secara sungguhsungguh keberadaan calon legeislatif dari disabilitas. keberadaanya hanya sebagai penggembira dalam ajang kontes pemilu. 3) Kekurangpahaman para petugas TPS dalam menyikapi calon pemilih disabilitas yang hadir di TPS maupun minimnya sarana prasarana pendukung untuk mewujudkan TPS yang akses bagi penyandang disabilitas.

Sedangkan contoh kasus dari kendala kultural antara lain: 1) Kultur masyarakat yang kurang inklusif dan cenderung sulit menerima perbedaan membuat calon pemilih enggan dating ke TPS karena masyarakat kurang bersikap menyambut dan cenderung menjadikan penyandang disabilitas pusat perhatian. 2) Kehadiran caleg dari unsur disabilitas cenderung kurang diminati karena stigma negatif kepada disabilitas masih cenderung kuat. dan 3) imbas dari sikap masyarakat dan pemerintah yang cenderung negatif selama ini, menyebabkan timbulnya sikap apatis dari penyandang disabilitas untuk ikut berpartisipasi dalam politik praktis.

\section{Upaya Mewujudkan Pemilu Akses Bagi Disabilitas}

Pemilu akses bagi penyandang disabilitas tidak bisa hanya dimaknai sebagai Pemilu yang bersifat aksesibel secara teknis pelaksanaan dalam pemilihan umum namun hasil pemilihan umum yang memang memberi dampak baik langsung maupun tidak langsung bagi penyandang disabilitas. Untuk itu, KPU Jember dalam hal ini selain berupaya memikirkan dan menciptakan pemilu yang akses dan ramah bagi disabilitas secara sarana dan prasarana, KPU Jember juga memasukkan isu-isu tentang disabilitas dalam debat pasangan calon, selain itu KPU Jember juga berupaya membangun komunikasi dengan organisasi disabilitas dalam memberikan dukungan dan saran terhadap penyelenggaraan pemilihan umum.

Sosialisasi penyelanggaraan pemilu yang melibatkan unsur disabilitas juga merupakan terobosan yang dilakukan KPU Jember untuk membangun kesepahaman bersama mewujudkan pemilu yang partisipatif oleh semua pihak termasuk unsur disabilits. KPU Jember juga telah membuat leflet terkait pemilu dengan tulisan Braille dan merangkul disabilitas tuli dengan melakukan sosialisai melalui bantuan penerjemah bahasa isyarat.

\section{Peran Penyandang Disabilitas Untuk Berpartisipasi Dalam Politik}

Peran penyandang disabilitas untuk berpartisipasi dalam politik dapat digolongkan menjadi dua sifat, yaitu peran secara individu dan peran secara organisasi. Secara individu, beberapa penyandang disabilitas di Kabupaten Jember memiliki motivasi yang kuat untuk aktif dalam politik praktis, baik sebagai kader parpol, calon legistlatif, panitia penyelenggara pemilu. Individu-individu ini secara aktif ikut memberikan wawasan dan informasi kepada penyandang disabilitas lainnya tentang perlunya disabilitas terlibat dalam pembangunan melalui partisipasi dalam politik, selain itu, mereka juga memiliki kemampuan untuk memberikan contoh kepada penyandang disabilitas lainnya 
agar menjadi penggerak di masyarakat sekitarnya.

Sejalan dengan hal tersebut, organisasi penyandang disabilitas juga memiliki peranan yang cukup penting bagi perpolitikan di Kabupaten Jember. Melalui organisasi ini, para penyandang disabilitas mendapat berbagai informasi mengenai pemilu yang aksesibel dan pentingnya disabilitas agar berpartisipasi dalam pemilu. Keberadaan organisasi penyandang disabilitas juga menjadi mediasi antara kepentingan calon penguasa dengan penyandang disabilitas itu sendiri, dan antara penyelenggara pemilu dengan penyandang disabilitas. Organisasi penyandang disabilitas juga secara tidak langsung menjadi evaluator dan auditor atas kinerja pemerintah khususnya dalam hal kebijakan terkait penyandang disabilitas untuk dijadikan pembahasan dalam debat calon Bupati di Kabupaten Jember dan juga untuk mengukur pemahaman dan rencana kerja calon legislatif yang berhubungan dengan isu-isu penyandang disabilitas.

Organisasi disabilitas di kabupaten Jember juga ikut aktif dalam melakukan kajian dan diskursus untuk membahas isu-isu penyelenggaran pemilu yang akses. Seminar dan Focus Group Discussion (FGD) juga dilaksanakan dengan mengikutsertakan unsur perguruan tinggi, tokoh masyarakat dan pihakpihak terkait untuk menghasilkan berbagai rekomendasi kepada pemerintah dan KPU. Di forum-forum inilah perbaikan dan upaya penyelenggaraan pemilu akses terus disuarakan dan diperbaiki.
SIMPULAN

Setelah melalui proses pengolahan dan analisis data, hasil penelitian menunjukkan bahwa Undang-Undang Nomor 7 Tahun 2017 tentang Pemilihan Umum dan Undang-Undang Nomor 8 Tahun 2016 tentang Penyandang Disabilitas telah mengakomodir hak penyandang disabilitas dalam berpolitik. Sedangkan kendala yang dihadapi untuk mewujudkan Pemilu yang akses dan partisipasi disabilitas dalam berpolitik berupa kendala struktural dan kultural dari pemerintah, masyarakat dan penyandang disabilitas. Adapun upaya yang telah dilakukan KPU Jember untuk mewujudkan pemilu akses adalah membangun komunikasi dengan organisasi disabilitas dan membentuk relawan demokrasi dari segmen disabilitas, sedangkan peran penyandang disabilitas baik secara pribadi maupun secara organisasi yakni dengan ikut aktif melaksanakan diskursus dan memberikan saran kepada pemerintah dan KPU untuk terwujudnya perbaikan pemilu akses.

\section{DAFTAR PUSTAKA}

Cevilla, C., G., (1993). Pengantar Metode Penelitian. Jakarta: Universitas Indonesia

Daulay, Z. (2013). Makna Konvensi Hak Penyandang Disabilitas (CRPD) dan Implementasinya dalam Kebijakan Pembangunan Daerah yang Inklusif serta Urgensi Perda Perlindungan Disabilitas. Makalah, Seminar Sehari.Padang: Auditorium Gubernuran Sumatera Barat. 
Mardalis. (1999). Metode Penelitian Suatu Pendekatan Proposal. Jakarta : Bumi Aksara

Mattila, M., Papageorgiou \& Achillefs. (2017). Disability, perceived discrimination and political participation. International Political Science Review. 38 (5) (onlie) dalam (https://journals.sagepub.com/do $\mathrm{i} / \mathrm{abs} / 10.1177 / 019251211665581$ 3) diakses pada tanggal 2 Januari 2019

Moleong J. L. (2010). Metodologi Penelitian Kualitatif. Edisi Revisi. Bandung: PT Remaja Rosdakarya

Muladi. (2009). Hak Asasi ManusiaHakekat, Konsep \& Implikasinya dalam Perspektif Hukum \& Masyarakat. Bandung: PT Refika Aditama, cetakan ketiga

Nazir, M. (2013). Metode Penelitian. Bogor: Ghalia Indonesia.

Zuriah, N. (2007). Metodologi Penelitian Sosial dan Pendidikan (Teori-Aplikasi). Jakarta: PT Bumi Aksara

Prince, M., J. (2012). Electoral Participation of Electors with Isabilities: Canadian Practices In A Comparative Context. (online) dalam

(https://elections.ca/content.aspx ?section=res\&dir=rec/part/spe\& document=index\&lang=e) diakses pada tanggal 2 Januari 2019

Robert. A., D. (2001). Perihal Demokrasi: $\quad$ Menjelajahi Theory dan Praktek Demokrasi secara Singkat. (Alih bahasa: A. Rohman Zainuddin). Jakarta: Yayasan Obor Indonesia.
Sugiyono, (2013). Metodelogi Penelitian Kuantitatif, Kualitatif Dan $R \& D$. Bandung: Alfabeta 